\title{
Kualitas Layanan sebagai Strategi Peningkatan Kepuasan Pengunjung Perpustakaan
}

\author{
Hervinda Raana Oktaviani ${ }^{1}$, Saifudin ${ }^{2}$, Rosana Eri Puspita ${ }^{3}$ \\ ${ }^{1}$ Prodi Perbankan Syariah, Fakultas Ekonomi dan Bisnis Islam IAIN \\ Salatiga, Jawa Tengah, Indonesia \\ ${ }^{2}$ Prodi Manajemen Bisnis Syariah, Fakultas Ekonomi dan Bisnis Islam, \\ IAIN Salatiga, Jawa Tengah, Indonesia \\ ${ }^{3}$ Prodi Manajemen Bisnis Syariah, Fakultas Ekonomi dan Bisnis Islam \\ IAIN Salatiga, Jawa Tengah, Indonesia \\ *Korespondensi: saifudin@iainsalatiga.ac.id
}

\begin{abstract}
This study aims to find out how much influence the quality of service reflected in responsiveness, assurance, empathy and physical evidence affect the library consumers. The data used in this study is using primary data by distributing questionnaires. The sample size in this study were 100 respondents who were library visitors. This study uses explanatory research that uses a quantitative approach with validity, reliability, T-test and F-test. The results of this study indicate that visitor satisfaction is positively and significantly affected by service quality. Recommendations resulting from this research for library practitioners are the preparation of library visit marketing strategies from the aspect of increasing library visitor satisfaction.
\end{abstract}

Keywords: $\quad$ service quality, satisfaction, library 


\begin{abstract}
Abstrak
Penelitian ini bertujuan untuk mengetahui seberapa besar pengaruh kualitas layanan yang tercermin dalam daya tanggap, jaminan, empati dan bukti fisik berpengaruh pada konsumen perpustakan. Data yang digunakan dalam penelitian ini yaitu menggunakan data primer dengan cara penyebaran kuisioner. Ukuran sampel dalam penelitian ini sebanyak 100 responden yang merupakan pengunjung perpustakaan. Penelitian ini menggunakan explanatory research yang menggunakan pendekatan kuantitatif dengan uji validitas, uji reabilitas, uji $\mathrm{T}$ dan uji F.Hasil penelitian ini menunjukkan bahwa kepuasan pengunjung dipengaruhi secara positif dan signifikan oleh kualitas layanan. Rekomendasi yang dihasilkan dari penelitian ini bagi praktisi perpustakaan adalah penyusunan strategi pemasaran kunjungan perpustakaan dari aspek peningkatan kepuasan pengunjung perpustakaan.
\end{abstract}

Kata kunci: kualitas pelayanan, kepuasan, perpustakaan

\title{
Pendahuluan
}

Dengan berkembangnya informasi yang sangat cepat sehingga menuntut Lembaga penyedia informasi untuk mengikuti perkembangan informasi. Oleh karena itu, pemerintah meningkatkan pelayanan pada jasa publik yang bertujuan untuk melayani masyarakat. Pemerintah membuat suatu badan sebagai penyedia layanan informasi jasa yaitu perpustakaan. Tujuan dibentuknya perpustakaan sebagai pelayanan publik adalah memberikan informasi-informasi yang dibutuhkan oleh masyarakat. Sebagai penyedia informasi, perpustakaan dituntut agar memberikan sistem pelayanan yang berkualitas.

Dengan kualitas layanan yang mendukung akan menjadi tolak ukur sebuah perpustakaan kepada kepuasan pengunjung perpustakaan. Pelayanan akan diberikan secara prima sehingga harapan pengunjung akan terpuaskan dengan jasa yang ia dapatkan. Yang dimaksud dengan pelayanan prima yaitu suatu layanan dengan standar kualitas yang tinggi dan selalu mengikuti perkembangan kebutuhan pelanggan setiap saat, secara konsisten dan akurat Nina Rahmayanti (2012:18). Ada empat unsur penting dalam konsep pelayanan prima: kenyamanan, ketepatan, keramahan, ketetapan. 
Eddy dan Solomon (2017) mengungkapkan bahwa peran pustakawan yang professional tidak lepas dari keterbukaan yang dibangun melalui model pelayanan yang baik. Agar kualitas pelayanan terpenuhi sesuai dengan harapan dan keinginan pengunjung perpustakaan, maka pemberi pelayanan jasa harus memenuhi berbagai indikator-indikator.

Perpustakaan diibaratkan sebagai jantung bagi sebuah lembaga. Bagaimana perpustakaan itu dikelola akan menjadi nilai bagi baik dan buruknya suatu lembaga. Perpustakaan dituntut agar memberikan pelayanan yang baik bagi para penggunanya.

Perpustakaan berkewajiban untuk memenuhi kebutuhan infomasi pengunjung yang didalamnya berisi untuk memuaskan harapan para pengunjungnya. Sehingga di dalamnya sudah ada kotak kritik saran untuk para pengunjung agar perpustakaan dapat lebih meningkatkan kualitas pelayanannya.

Namun, walaupun sudah ada kotak untuk kritik dan saran, tetap saja masih banyak kekurangan dalam pemberian layanan jasa. Adapun beberapa masalah yang biasanya ditemui para pengunjung yaitu seperti petugasnya yang kurang ramah, kurang lengkapnya informasi yang dibutuhkan seperti buku dan jumlah buku yang terbatas. Atau bahkan bisa saja buku yang harusnya berada di rak A namun ada di rak lain, hal itu membuat pengunjung menjadi tidak puas dengan pelayanannya.

Fakta ini dapat menggambarkan bahwa pengunjung dapat menilai pelayanan yang diberikan itu baik sesuai keinginan dan harapan atau buruk. Maka penelitian sangat relevan untuk dikaji sebagai bahan dalam pengambilan keputusan bagi para stakeholder.

\section{Tinjauan Pustaka}

\section{Konsep kualitas layanan perpustakaan}

Menurut Sharma dalam Fatmawati (2014:38) bahwa kualitas layanan perpustakaan merupakan kepuasan yang diperoleh setiap pemustaka atau pengunjung dilihat dari kelengkapan, ketelitian, dan layanan yang terbaik 
dari petugas perpustakaan. Dalam kualitas pelayanan dapat diukur dalam berbagai aspek yang berhubungan dengan pengunjung dan sumber daya perpustakaan.

Dengan demikian, kualitas pelayanan sebagai tolak ukur bagi keberhasilan suatu instansi, perusahaan maupun organisasi yang berfokus kepada kepuasan pelanggan dengan pemberian layanan jasa secara prima sehingga harapan pengunjung akan terpuaskan dengan layanan yang mereka terima.

Lupiyadi (2006:182) membagi kualitas layanan menjadi lima dimensi dalam pengukurannya Pertama, keandalan yaitu hal ini berhubungan dengan bagaimana perpustakaan dapat memberikan layanan yang akurat dan dapat dipercaya. Kedua, bukti fisik yaitu hal ini berhubungan dengan kualitas fisik, sarana maupun prasarana yang tersedia. Ketiga, daya tanggap: yaitu kecepatan dalam memproses suatu informasi yang didapat. Keempat, jaminan yaitu hal ini meliputi kesopanan, keramahan, dan pengetahuan petugas.kelima, empati yaitu hal ini menyangkut dengan kesiapan petugas dalam menanggapi masalah yang ada.

\section{Layanan Perpustakaan}

Terdapat tujuh layanan perpustakaan yaitu layanan silang layan, layanan peminjaman dan pengembalian, layanan rujukan, layanan internet, layanan terjemahan, layanan bimbingan, dan layanan konsultasi. Layanan silang layan adalah hubungan timbal balik antara perpustakaan dengan pengunjung. Layanan peminjam dan pengembalian adalah layanan yang minimal haru ada di sebuah perpustakaan. Layanan rujukan adalah layanan yang berhubungan dengan buku yang dijadikan koleksi sebagai referensi untuk dibaca di tempat atau di perpustakaan, dan tidak boleh dipinjamkan. Layanan internet adalah layanan yang diberikan oleh perpustakaan agar pengunjung lebih mudah dalam mencari sebuah informasi. Layanan terjemahan adalah layanan yang terjadi apabila pengunjung mengalamai kesulitan dalam bahasa di dalam koleksi buku. Layanan bimbingan adalah layanan untuk memenuhi kebutuhan pengunjung akan informasi. Layanan 
konsultasi adalah layanan yang diberikan apabila ada seorang pengunjung, kelompok, atau instansi yang ingin mendirikan perpustakaan (Achmad, dkk., 2012:22).

Dari penjelasan diatas dapat diketahui bahwa layanan merupakan hal yang sengat penting bagi penyedia layanan jasa seperti perpustakaan. Karena tanpa layanan yang memadai perpustakaan tidak akan bisa beroperasi dengan baik.

\section{Kepuasan Pengunjung}

Apabila pengunjung ditanya mengenai penilaian kepuasan mereka terhadap perpustakaan maka akan muncul banyak sekali jawaban yang berbeda-beda. Karena setiap pengunjung memiliki cara pandang dalam menilai kualitas. Tetapi ada beberapa kesamaan yang diinginkan para pengunjung, seperti pengunjung mengharapkan kenyamanan dalam perpustakaan, pengunjung mengharapkan koleksi buku yang banyak. pengunjung mengaharapkan petugas yang ramah, dan tanggap, pengunjung mengharapkan akses internet dengan cepat

Tjiptono dan Chandra (2011:314) menawarkan beberapa cara pengukuran dalam kepuasan pengunjung. Pertama, Sistem keluhan dan saran. Sistem yang diberikan kepada pengunjung agar mereka bebas menyampaikan keluh kesahnya terhadap layanan kita dengan kotak saran, website, kartu komentar dan hal lainnya yang ditempatkan di tempat strategis. Kedua, Ghost shopping (mystery shooping) yaitu cara yang memakai jasa orang-orang agar menyamar sebagai pengunjung maupun pesaing kita, agar bisa menilai bagaimana layanan dan kualitas produk kita. Ketiga, Lost customer analysis yaitu cara yang dilakukan dengan melakukan analisis tentang pelanggan yang sudah tidak membeli atau menggunakan layanan kita lagi. kemudian mencari cara agar bisa memperbaikinya. Keempat, Survey kepuasan pelanggan, yaitu riset yang dilakukan dengan survey kepada para pelanggan seperti wawancara, menilai melalui website, telepon, e-mail. Hal ini akan memberikan umpan balik secara langsung dan positif karena kita akan dianggap memberikan perhatian kepada para pelanggan kita. 


\section{Hubungan kualitas pelayanan terhadap kepuasan pengunjung}

Kotler dan Keller (2009:138) menemukan adanya hubungan antara kualitas dan kepuasan yaitu jika semakin baik kualitasnya maka akan berpengaruh terhadap kepuasan yang diperoleh. Perpustakaan sebagai penyedia layanan jasa harus memiliki kualitas yang baik sehingga perpustakaan akan dinilai baik oleh pengunjung. Sutarno (2004:71) menyebutkan bahwa kualitas layanan yaitu cepat, mudah dan memberikan kepuasan. Berbeda dengan penelitian Kasdi dan Saifudin (2019) yang menemukan bahwa kualitas layanan (CARTER) tidak berpengaruh terhadap kepuasan pengunjung. Sehingga penelitian tentang hubungan pelayanan dan kepuasan pengunjung penting untuk dilanjutkan lebih mendalam.

Kualitas pelayanan memiliki hubungan yang erat terhadap kepuasan pengunjung, sehingga ada beberapa indikator yang dipercaya dapat menumbuhkan kepuasan pengunjung seperti keandalaan, daya tanggap, jaminan, empati, dan bukti fisik. Terdapat model konsep kualitas pelayanan terhadap kepuasan pengunjung seperti gambar dibawah ini:

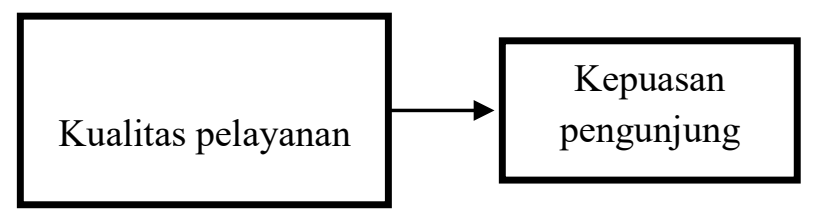

\section{Gambar 1: Model Penelitian}

Model hipotesisnya dapat dilihat pada gambar 2 seperti dibawah ini: 


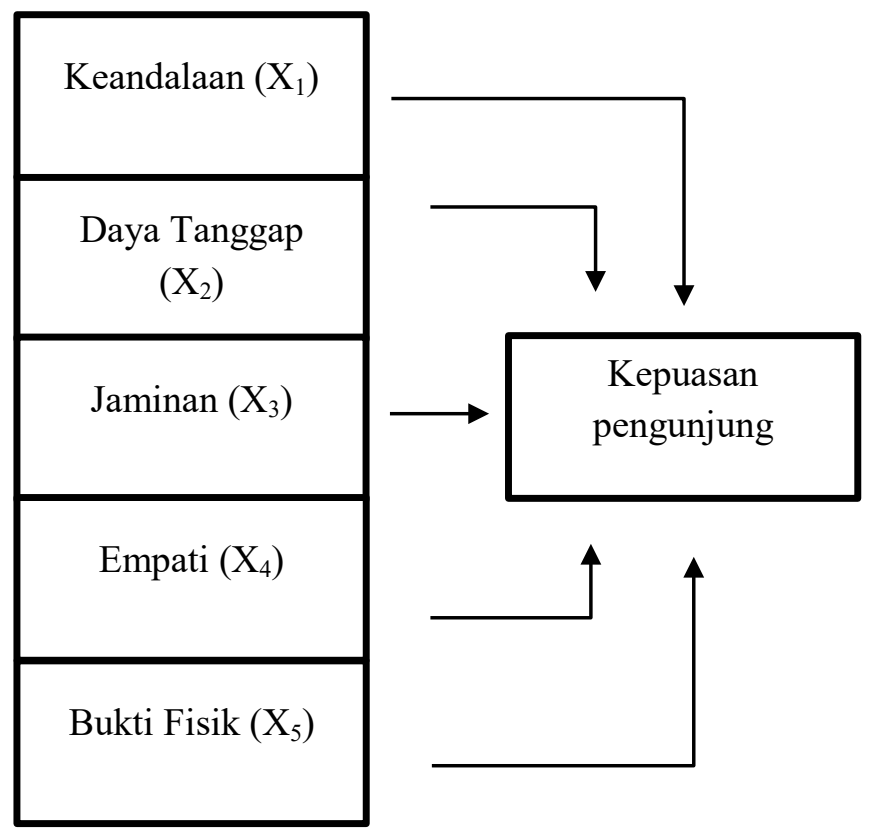

Gambar 2: model hipotesis

Dari gambar diatas dapat diambil rumusan hipotesis sebagai berikut:

1) Diduga keandalan berpengaruh terhadap kepuasan pengunjung perpustakaan

2) Diduga daya tanggap berpengaruh terhadap kepuasan pengunjung perpustakaan

3) Diduga jaminan berpengaruh terhadap kepuasan pengunjung perpustakaan

4) Diduga empati berpengaruh terhadap kepuasan pengunjung perpustakaan

5) Diduga bukti fisik berpengaruh terhadap kepuasan pengunjung perpustakaan 


\section{Metode}

Jenis penelitian ini menggunakan explanatory research yang menggunakan pendekatan kuantitatif. Populasi dalam penelitian ini adalah pengunjung perpustakaan. Dan ukuran sampel yang digunakan berjumlah 100 responden. Teknik pengambilan sampel penelitian ini menggunakan random Sampling.

Analisis data yang digunakan dalam penelitian ini dilakukan dalam baberapa tahap. Pertama, uji validitas. Pengujian ini digunakan untuk menguji validitas dari instrumen penelitian yang digunakan dalam pengumpulan data. Kedua, uji reabilitas. Pengujian ini digunakan untuk mengukur tingkat kepercayaan sebuah instrument penelitian. Ketiga, uji asumsi klasik, uji regresi, uji koefisien determinasi, uji korelasi, dan uji regresi. Tahap ketiga ini bertujuan untuk mengukur apakah ada pengaruh pada variabel bebas yang terdiri dari keandalan, bukti fisik, jaminan, empati, dan daya tanggap kepada variabel terikat (kepuasan pengunjung) dengan menggunakan uji $\mathrm{F}$ dan uji T untuk mengetahui masing-masing variabel berpengaruh terhadap kepuasan pengunjung $(\mathrm{Y})$.

\section{Hasil dan Pembahasan}

Berdasarkan pengolahan data menggunakan SPSS didapatkan demografi responden pada tabel 1 sebagai berikut:

Tabel 1. Informasi Demografis

\begin{tabular}{ll}
\hline Demografis & Persentase \\
\hline Jenis kelamin & \\
Laki-laki & 60.0 \\
Perempuan & 40.0 \\
\hline Kunjungan ke perpustakaan & \\
1 kali & 11.0 \\
2 kali & 15.0 \\
3 kali & 17.0 \\
Lebih dari 3 kali & 57.0 \\
\hline
\end{tabular}

Sumber: Olah Data 2019 
Dalam Tabel 1 dapat dilihat bahwa jumlah responden yaitu 100 mahasiswa yang mana $60 \%$ berjenis kelamin laki-laki dan $40 \%$ perempuan. Dan pada bagian berapa kali kunjungan ke perpustakaan di dapat hasil dalam 1 kali kunjungan sebanyak 11\%, 2 kali kunjungan 15\%, 3 kali kunjungan 17\% dan lebih dari 3 kali kunjungan sebanyak 57\%.

Tabel 2. Hasil KMO dan Bartlett of Sphericity

\begin{tabular}{ll}
\hline Pengujian & Nilai \\
\hline Sample Adequacy KMO & 0,880 \\
Bartlett of Sphericity & 0,000 \\
\hline
\end{tabular}

Sumber: Olah Data 2019

Dari hasil uji KMO dan Bartlett di atas maka didapatkan nilai dari KMO yaitu 0,880 yang artinya nilainya lebih baik. Dan nilai Bartlett yaitu 0,000 yang menyatakan bahwa hasilnya signifikan. Dari uji validitas maka dapat dikatakan bahwa penelitian ini valid.

Dalam mengukur kuisioner, digunakan pemilihan jawaban dengan skala Likert 5 poin. Skala yang digunakan mempunyai penilaian dimana 1 (sangat tidak setuju), 2 (tidak setuju), 3 (netral), 4 (setuju), dan 5 (sangat setuju). Terdapat uji validitas dan reabilitas untuk menguji instrumen penelitian. Hasil dari uji validitas dan uji reabilitas dapat dilihat pada Tabel 2 dan Tabel 3.

\section{Tabel 3. Uji Validitas dan Reliabilitas Konvergen}

\section{Keandalan $(\mathrm{CR}=\mathbf{0 . 6 8 5})$}

\section{Barang}

Memuat

Petugas cepat dan tanggap dalam memberikan layanan 0,744

Penutupan dan pembukaan perpustakaan selalu tepat pada waktunya 0,491

Petugas selalu siap dan sigap dalam ketika kita membutuhkan informasi 


\section{Barang}

Memuat

Daya Tanggap $(\mathrm{CR}=\mathbf{0 . 7 8 8})$

Petugas bersikap sabar jika kita meminta informasi

0,897

Respon petugas baik terhadap kritik dan saran

Jaminan $(C R=0.564)$

Ruangan perpustakaan sudah sesuai harapan

Semua petugas bersikap sopan kepada pengunjung

0,898

Empati $(\mathrm{CR}=\mathbf{0 . 7 2 5})$

Cara petugas dalam berkomunikasi dengan pengunjung sudah $\quad 0,900$ menggunakan bahasa yang sopan

Petugas bersikap ramah

Bukti Fisik ( $\mathrm{CR}=\mathbf{0 . 7 8 5}$ )

Perpustakaan sudah bersih

Buku-buku dalam perpustakaan sudah lengkap

0,786

Buku-buku sudah tertata rapi dalam rak-rak yang disediakan

0,690

Letak perpustakaan sudah strategis

0,691

Kepuasan Pengunjung $(\mathrm{C}=\mathbf{0 . 7 0 0})$

0,745

Sikap petugas dalam melayani pengunjung sudah sesuai

dengan harapan

0,913

Harapan pengunjung sudah terpenuhi dalam pelayanan

0,917 perpustakaan

Sumber: Olah Data 2019

Table 3 menunjukkan hasil dari uji reabilitas dari nilai Alpha Cronbach. Dari tabel diatas dapat dilihat bahwa nilai dari variabel keandalan adalah 0,685 , nilai dari variabel daya tanggap adalah 0,788 , nilai dari variabel jaminan adalah 0,564, nilai dari variabel empati adalah 0,725 , nilai dari variabel bukti fisik adalah 0,785 , nilai dari variabel kepuasan pengunjung yaitu 0,700. Dari nilai Cronbach Alpha, which melebihi 0,7 sehingga dapat dikatakan bahwa intrumen penelitian ini dapat diandalkan.

Untuk membuktikan hipotesis yang ada maka perhitungan ini menggunakan uji regresi. Uji ini dilakukan untuk mengukur variabel independent terhadap variabel dependen. Dan uji ini dibantu dengan SPSS versi 23. Dapat dilihat pada Tabel 4. 


\section{Table 4. Determinant Coefficient and Adjusted R Square and Result of t-test, and F-test}

\begin{tabular}{lrrrrr}
\hline & K to KP & DT to KP & to KP & E to KP & BF to KP \\
\hline Determinant Coefficient and Adjusted R & & & & & \\
R & 0.597 & 0.713 & 0.675 & 0.660 & 0.623 \\
R2 & 0.356 & 0.508 & 0.456 & 0.435 & 0.388 \\
Adjusted R Square & 0.350 & 0.503 & 0.450 & 0.430 & 0.382 \\
Standardized Coefficient Beta & & & & & \\
T & 7.362 & 10.056 & 9.055 & 8.691 & 7.881 \\
Sig. & 0.000 & 0.000 & 0.000 & 0.000 & 0.000 \\
Result of F test & & & & & \\
F & 54.196 & 101.124 & 81.995 & 75.536 & 62.108 \\
Sig. & 0.000 & 0.000 & 0.000 & 0.000 & 0.000 \\
\hline
\end{tabular}

Dari hasil tes yang pertama, didapatkan nilai $\mathrm{R}$ yaitu 0,597 , nilai R2 adalah 0,356, dan nilai Adjusted R Square adalah 0,350. Dan dari nilai Adjusted R Square dapat dilihat bahwa 35\% dari variabel kepuasan dipengaruhi oleh keandalan. Sedangkan 65\% dipengaruhi oleh variabel yang lainnya.

Keandalaan berpengaruh positif dan signifikan terhadap kepuasan pengunjung. Karena dari hasil uji regresi didapat nilai 0,356, dengan nilai t hitung sebesar 7,362 dan sig sebesar 0,000 yang dimana sig ini lebih kecil dari 0,05. Yang berarti bahwa apabila keandalan dapat ditingkatkan maka kepuasan pengujung juga akan meningkat. Uji $\mathrm{F}$ juga dilakukan dalam tes yang pertama, nilai $\mathrm{F}$ yaitu 54,196 dengan nilai sig 0,000. Hasil ini menunjukkan bahwa keandalan berpengaruh pada kepuasan pengunjung.

Dari hasil tes yang kedua, didapatkan nilai $\mathrm{R}$ yaitu 0,713 , nilai R2 adalah 0,508, dan nilai Adjusted R Square adalah 0,503. Dan dari nilai Adjusted R Square dapat dilihat bahwa 50\% dari variabel kepuasan dipengaruhi oleh daya tanggap. Sedangkan 50\% dipengaruhi oleh variabel yang lainnya.

Daya tanggap berpengaruh positif dan signifikan terhadap kepuasan pengunjung. Karena dari hasil uji regresi didapat nilai 0,508 , dengan nilai t 
hitung sebesar 10,056 dan sig sebesar 0,000 yang dimana sig ini lebih kecil dari 0,05 . Yang berarti bahwa apabila daya tanggap dapat ditingkatkan maka kepuasan pengujung juga akan meningkat. Uji $F$ juga dilakukan dalam tes yang kedua, nilai F yaitu 101,124 dengan nilai sig 0,000. Hasil ini menunjukkan bahwa daya tanggap berpengaruh pada kepuasan pengunjung.

Dari hasil tes yang ketiga, didapatkan nilai R yaitu 0,675, nilai R2 adalah 0,456, dan nilai Adjusted R Square adalah 0,450. Dan dari nilai Adjusted R Square dapat dilihat bahwa 45\% dari variabel kepuasan dipengaruhi oleh jaminan. Sedangkan 55\% dipengaruhi oleh variabel yang lainnya.

Jaminan berpengaruh positif dan signifikan terhadap kepuasan pengunjung. Karena dari hasil uji regresi didapat nilai 0,456 , dengan nilai t hitung sebesar 9,055 dan sig sebesar 0,000 yang dimana sig ini lebih kecil dari 0,05 . Yang berarti bahwa apabila jaminan dapat ditingkatkan maka kepuasan pengujung juga akan meningkat. Uji F juga dilakukan dalam tes yang ketiga, nilai $\mathrm{F}$ yaitu 81,995 dengan nilai sig 0,000 . Hasil ini menunjukkan bahwa jaminan berpengaruh pada kepuasan pengunjung.

Dari hasil tes yang keempat, didapatkan nilai $\mathrm{R}$ yaitu 0,660 , nilai R2 adalah 0,435, dan nilai Adjusted R Square adalah 0,430. Dan dari nilai Adjusted R Square dapat dilihat bahwa 43\% dari variabel kepuasan dipengaruhi oleh empati. Sedangkan 57\% dipengaruhi oleh variabel yang lainnya.

Empati berpengaruh positif dan signifikan terhadap kepuasan pengunjung. Karena dari hasil uji regresi didapat nilai 0,435 , dengan nilai t hitung sebesar 8,691 dan sig sebesar 0,000 yang dimana sig ini lebih kecil dari 0,05. Yang berarti bahwa apabila empati dapat ditingkatkan maka kepuasan pengujung juga akan meningkat. Uji $\mathrm{F}$ juga dilakukan dalam tes yang keempat, nilai F yaitu 75,536 dengan nilai sig 0,000. Hasil ini menunjukkan bahwa empati berpengaruh pada kepuasan pengunjung.

Dari hasil tes yang kelima, didapatkan nilai $\mathrm{R}$ yaitu 0,623 , nilai $\mathrm{R} 2$ adalah 0,388, dan nilai Adjusted R Square adalah 0,382. Dan dari nilai Adjusted R Square dapat dilihat bahwa 38\% dari variabel kepuasan dipengaruhi oleh 
bukti fisik. Sedangkan 62\% dipengaruhi oleh variabel yang lainnya.

Bukti fisik berpengaruh positif dan signifikan terhadap kepuasan pengunjung. Karena dari hasil uji regresi didapat nilai 0,388, dengan nilai t hitung sebesar 7,881 dan sig sebesar 0,000 yang dimana sig ini lebih kecil dari 0,05. Yang berarti bahwa apabila bukti fisik dapat ditingkatkan maka kepuasan pengujung juga akan meningkat. Uji $\mathrm{F}$ juga dilakukan dalam tes yang kelima, nilai F yaitu 62,108 dengan nilai sig 0,000. Hasil ini menunjukkan bahwa bukti fisik berpengaruh pada kepuasan pengunjung.

\section{Kesimpulan}

Dari penelitian dapat diambil kesimpulan sebagai berikut:

1) Variabel keandalan, daya tanggap, jaminan, empati, dan bukti fisik memiliki pengaruh positif dan signifikan terhadap kepuasan pengunjung. Hal ini menunjukkan bahwa kepuasan pengunjung perpustakaan IAIN Salatiga tergantung dari kualitas layanan yang diberikan.

2) Variabel keandalan tidak secara dominan mempengaruhi kepuasan pengunjung karena hanya berpengaruh 35\% terhadap kepuasan pengunjung. Artinya, kepuasan pengunjung dapat didapatkan dengan variabel yang lainnya.

3) Variabel daya tanggap adalah variabel yang paling berpengaruh terhadap kepuasan pengunjung dengan didapatkan nilai sebanyak $50 \%$.

\section{Saran}

Penulis memberikan saran kepada manajemen perpustakaan dan akademisi sebagai berikut:

1) Perpustakaan FEBI IAIN Salatiga diharapkan untuk mempertahankan atau meningkatkan kualitas layanan mereka karena dengan meningkatkan kualitas layanan maka kepuasan pengujung akan meningkat.

2) Perpustakaan FEBI IAIN Salatiga digunakan untuk melayani masyarakat sehingga untuk kemajuan perpustakaan dibutuhkan kritik dan saran dari pengunjung perpustakaan yang hendaknya memberikan kritik dan saran 
yang kritis dan sesuai dengan kualitas layanan yang mereka dapatkan.

3) Diaharapkan akan ada penelitian selanjutnya yang akan meneliti lebih jauh tentang kepuasan pengujung perpustakaan. Karena dalam penelitian ini kualitas layanan berpengaruh terhadap kepuasan pengunjung maka di harapkan akan ada factor lain yang dapat mempengaruhi kepuasan pengunjung seperti kualitas layanan syariah.

\section{Daftar Pustaka}

Achmad et al.2012. Layanan cinta: Perwujudan layanan prima perpustakaan. Jakarta:Sagung Seto.

Eddy, M.A., \& Solomon, D., 2017. Leveraging Librarian Liaison Expertise in a New Consultancy Role, The Journal of Academic Librarian ship. Vol.34 No.2. hlm.121-127.

Dedy Douglas Harianja, Rita Rahmawati, Moch. Abdul Mukid. 2015. Analisis Kesenjangan Kualitas Pelayanan terhadap pengunjung perpustakaan Universitas Diponegoro. Jurnal Gaussian.Vol.4 No.4. hlm.775-784

Dwi Susilo dan Sugiarto. 2017. Analisis tingkat kepuasan pengunjung perpustakaan universitas Pekalongan. Program Studi Manajemen Fakultas Ekonomi. Universitas Pekalongan. Vol.31 No.1 hlm.27-35

Endang Fatmawati. 2014. Mata Baru Penelitian Perpustakaan dari Servqua 1 ke Libqual+TM,. Jakarta: Sagung Seto, hlm.329-348

Esty Naruliza, Faradillah Sandhy Purwaningsih. 2017. Kualitas pelayanan berpengaruh terhadap kepuasan pengunjung perpustakaan. JEMASI. Fakultas Ekonomi Universitas IBA. Vol.3 No.2. hlm.221-236

Fandy Tjiptono. 2002. Manajemen Jasa. Edisi II. Yogyakarta: ANDI Haning Tri N, Lely Indah M, Hermintatik. 2016. Pengaruh Kualitas Pelayanan Terhadap Kepuasan Pemustaka (Studi pada Perpustakaan umum dan Arsip Kota Malang). Jurnal Administrasi Publik Universitas Brawijaya Malang, Vol.3 No.5, hlm.789-794.

Imam Ghozali. 2011. Aplikasi Analisis Multivariate dengan Program SPSS. Semarang:Badan Penerbit Universitas Diponegoro. 
Kasdi, A., Saifudin, S., Influence of Sharia Service Quality, Islamic Values, and Destination Image toward Loyalty Visitors' on Great Mosque of Demak. International Journal of Islamic Business and Economics (IJIBEC), [S.1.], p. 115-126, nov. 2019. ISSN 2615-420X. doi: https:// doi.org/10.28918/ijibec.v3i2.1909.

Kotler, P dan Keller K.L. 2009. Manajemen Pemasaran. Edisi ke-13. Jilid 1. Jakarta: Penerbit Erlangga.

Kotler, P dan Keller K.L. 2009. Manajemen Pemasaran. Edisi ke-13. Jilid 2. Jakarta: Penerbit Erlangga.

Kotler, Philip. 2002. Manajemen Pemasaran. Jilid I. Edisi Milenium. Jakarta: Prenhalindo.

Lupiyoadi, Rambat. 2013 . Manajemen Pemasaran Jasa. Edisi ke-3. Jakarta: Salemba Empat.

M. Salim. 2014. Pengaruh Layanan Sirkulasi Terhadap Kepuasan Pengguna Perpustakaan IAIN Sunan Ampel Surabaya. Skripsi, Fakultas Ilmu Tarbiyah Dan Keguruan Jurusan Kependidikan Islam IAIN Sunan Ampel Surabaya.

Nina Rahmayanty. 2012. Manajemen Pelayanan Prima. Yogyakarta: Graha Ilmu. hlm.18-242.

Rhoni Rodin. 2015. Kepuasan Pemustaka Terhadap Layanan Rujukan (Studi Kasus di Perpustakaan STAIN Curup. Skripsi, Prodi Ilmu Perpustakaan dan Informasi.

Ratna, Endang Meiliani. 2018. Pengaruh Fasilitas Kantor, Kualitas Pelayanan dan Standar Operasional prosedur Terhadap Tingkat Kepuasan Pengunjung pada Dinas Perpustakaan dan Kearsiapan daerah Kabupaten Batanghari. Jurnal Ilmiah Ekonomi dan Bisnis. STIE Graha Karya Muara Bulian, Jambi, Indonesia. Vol.9 No.2.hlm 147-152

Sugiyono. 2013. Metode Penelitian Kuantitatif, Kualitatif, dan R\&D. Cetakan.18. Bandung:Alfabeta.

Sutarno, NS. 2004. Manajemen Perpustakaan: Suatu Pendekatan Praktik. Jakarta:Samitra Media Utama. 
Yuli Wulandari 2015. Pengaruh Kualitas Layanan Perpustakaan Terhadap Kepuasan Siswa MTs 01 Banyuputih Batang. Skripsi, Fakultas Ilmu Tarbiyah Dan Keguruan Jurusan Manajemen Pendidikan Islam UIN Walisongo Semarang. 